\title{
Frontal infrared thermography in healthy individuals and chronic migraine patients: reliability of the method
}

\begin{tabular}{|r|l|}
\hline Journal: & Cephalalgia \\
\hline Manuscript ID & CHA-00474-OA-2017.R2 \\
\hline Danuscript Type: & Original Article \\
\hline Complete List of Authors: & $\begin{array}{l}\text { Antonaci, Fabio; Universita degli Studi di Pavia, Brain and behavioural } \\
\text { sciences; Fondazione Istituto Neurologico Nazionale C Mondino Istituto di } \\
\text { Ricovero e Cura a Carattere Scientifico, Headache center } \\
\text { Rossi, Elena; Politecnico di Milano, Dipartimento di Elettronica, } \\
\text { Informazione e Bioingegneria } \\
\text { Voiticosovich-Iosob, Cristina; State Medical and Pharmaceutical University } \\
\text { "Nicolae Testemitanu", Medicine } \\
\text { Dalla Volta, Giorgio; Istituto Clinico Citta Di Brescia, UO Neurologia } \\
\text { Marceglia, Sara; Universita degli Studi di Trieste Dipartimento di } \\
\text { Ingegneria e Architettura, Dipartimento di Ingegneria e Architettura; } \\
\text { Ospedale Maggiore Policlinico, UO Neurofisiopatologia }\end{array}$ \\
\hline Key Words: & $\begin{array}{l}\text { Frontal thermography, chronic migraine, cold patch, standard procedure, } \\
\text { reliability }\end{array}$ \\
\hline &
\end{tabular}



migraine patients: reliability of the method

3

4

5

6

7

\section{Frontal infrared thermography in healthy individuals and chronic}

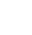

Fabio Antonaci, $\mathrm{MD}, \mathrm{PhD}^{1}$, Elena Rossi, $\mathrm{PhD}^{2,3}$, Cristina Voiticovschi-Iosob, $\mathrm{MD}^{4}$, Giorgio Dalla Volta, $\mathrm{MD}^{5}$, and Sara Marceglia, $\mathrm{PhD}^{6^{*}}$ 6

${ }^{1}$ Headache Centre, C. Mondino National Institute of Neurology Foundation, IRCCS, Department of Brain and Behavioral Sciences University of Pavia, Italy.

${ }^{2}$ Dipartimento di Elettronica, Informazione e Bioingegneria. Politecnico di Milano. Milan, 10 Italy.

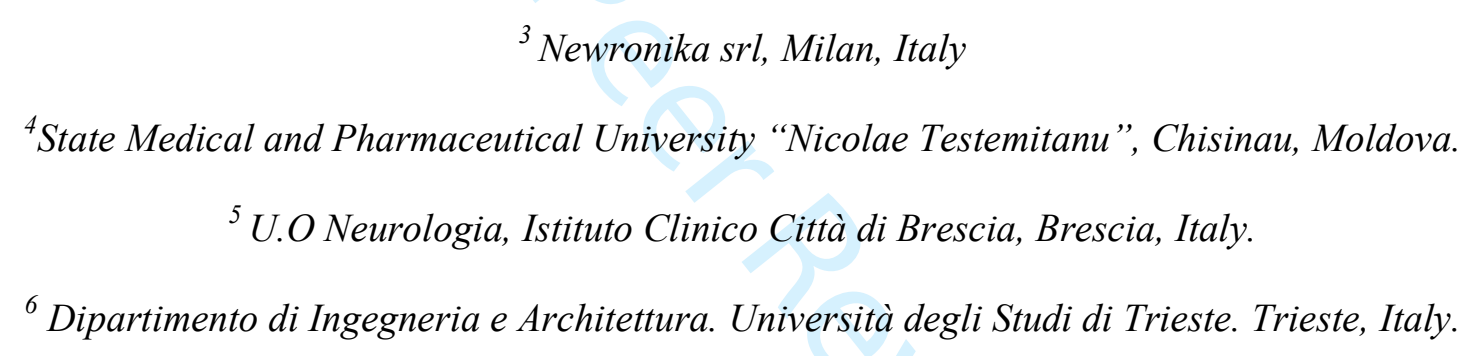




\section{Abbreviations}

2 AI - Asymmetry Index

3 ANOVA - analysis of variance

$4 \quad$ BMS - between-subjects mean square

5 CV - Coefficient of Variation

6 EMS - residual mean square

$7 \quad$ FIT - Frontal Infrared Thermography

8 ICC - intra-class correlation coefficient

9 JMS - within-subjects mean square

10 tDCS - transcranial direct current stimulation

11 VAS - Visual Analogue Scale

12

13

14 


\section{$1 \quad \underline{\text { Abstract }}$}

2 Background: The use of Frontal infrared thermography in the diagnosis of primary

3 headaches provided scattering results due to measurement fluctuations and different types of

4 headaches or research protocols.

5 Objective: This study aims to assess the reliability of Frontal infrared thermography in

6 healthy individuals and provide a preliminary evaluation in chronic migraine patients using a

7 commercial infrared thermal camera.

8 Methods: Thermographic images were acquired in 20 controls and 15 patients at 3 9 consecutive time-points in two daily sessions. The Side Difference and Asymmetry Index 10 parameters were defined. The reproducibility of the measurements, the correlation of 11 Asymmetry Index and Side Difference with clinical evaluations and patient perceptions, and 12 the ability of the parameters to discriminate between patients and controls were investigated.

13 Results: We reported a good reproducibility of the measurements (Inter-class Correlation 14 Coefficient $>0.75$ and Coefficient of Variation $<13.4 \%$ ), independent from external factors. 15 The Side Difference was significantly different between patients and controls $(p<0.001)$. The 16 Asymmetry Index showed good correlation with the side of unilateral pain $(p=0.0056)$.

17 Conclusions: Frontal infrared thermography can be used to quantify the difference between 18 the right and the left side of frontal vascular changes in chronic migraine patients, provided 19 that standardized conditions are satisfied. 


\section{Introduction}

2 Infrared Thermography detects infrared light emitted by the human body to visualize changes

3 in heat due to abnormalities in the skin surface blood flow of diseased areas. This non-

4 invasive and non-radiative imaging technique has different clinical applications including the

5 detection of circulatory and/or inflammatory disorders such as rheumatoid arthritis,

6 Raynaud's disease or osteoarthritis of the knee ${ }^{1}$. It was also demonstrated that thermography

7 is able to capture thermal gradient in facial areas characterizing healthy individuals ${ }^{2}$.

8 However, the literature investigating the use of external carotid region (forehead) thermal

9 imaging for the characterization of vascular headaches did not reach consistent results due to 10 different types of headache evaluated, different timing of patients' evaluation (during 11 headache attack or in headache free interval), different technologies used for image 12 acquisition, and different methods for imaging or statistical analysis.

13 In 1986, Swerdlow and Dieter ${ }^{3}$ comparing electronic thermography between 275 headache 14 patients and 45 controls, defined the "Cold Patch" as a region of the face where the 15 temperature is cooler (less than $0.5^{\circ} \mathrm{C}$ ) than the surrounding areas ${ }^{3,4}$. The presence of the cold 16 patch is more frequent in vascular headaches than in healthy subjects or patients with tension 17 type headache, psychogenic headaches or post-traumatic headaches.

18 There is an open question on whether the cold patch is a "fixed" entity ${ }^{5}$ or whether it 19 decreases with therapy ${ }^{6,7}$. In fact, whereas according to Swerdlow and Dieter, "the vascular 20 cold patch is independent of prognosis and is most likely a permanent element of a vascular 21 headache sufferer's facial thermal pattern", in 1991, Dalla Volta et al. ${ }^{7}$ suggested that the 22 "cold patch" in vascular headache patients is ipsilateral to the prevailing side of pain and that 23 the cooler area decreased after 6 months of prophylactic therapy. The differences observed by 24 the two groups may be explained in terms of experimental protocol and patient's selection 25 that introduced a higher variability in the cold patch response ${ }^{7}$. 
1 Anyway, there is large consensus on the fact that the cold patch represents an asymmetry in

2 the forehead of migraine patients. Unfortunately, the location of the cold patch is seldom

3 related to the side of the pain ${ }^{5}$ probably due to the variation of temperature during headache

4 attack or due to the lateralization of the headache (unilateral or bilateral) as measured by

5 Drummond and Lance ${ }^{8,9}$.

6 Finally, FIT, in conjunction with nitroglycerine administration, was suggested as a novel non-

7 invasive approach to study vascular processes underlying headaches ${ }^{10}$.

8 Taken together, all these studies demonstrate that FIT can be used as diagnostic tool in

9 migraine with and without aura, in cluster headache and in other headache types.

10 In the light of previous observations and of new possible therapeutic applications, the present

11 study has two primary end points: (1) to evaluate the reliability of FIT measurements in

12 controls and chronic migraine patients using modern commercial infrared thermal camera; (2)

13 to verify whether FIT-based parameters correlate both with the visual evaluation of FIT by an

14 expert clinician and with patient's perception of pain side (at least in case of unilateral pain).

15

16

\section{Subjects}

18

19 testing.

\section{Materials and methods}

Thirty five right handed volunteers (26 females and 9 males) with a mean age of $35 \pm 11.6$ years (range: 20-55) were enrolled at the Headache centre of the Fondazione IRCCS Istituto Neurologico Nazionale Casimiro Mondino. All the subjects were not medicated at the time of

215 of the 35 volunteers ( 3 males) suffered from chronic migraine with medication overuse, as assessed according to the IHS Classification ${ }^{11}$. They were examined while hospitalized and during a washout period from analgesics or other symptomatic treatment, including nonheadache medication. Patients were not on dietary/smoking restrictions ahead of 
1 measurements. Patients did not use preventive treatment and underwent daily parenteral

2 detoxification (saline, cyanocobalamin, folic acid, nicotinammide, glutathione, delorazepam

3 and metoclopramide on demand). Patients were assessed on the second or third day after

4 symptomatic medication withdrawal that started on the day of hospital admission. No

5 symptomatic medication was allowed during the evaluation period but local ice bag (at least

6 one day apart from the examination). Hence, patients were generally with headache during the

7 examination. Pain severity was evaluated before each examination on a $0-3$-score Visual

8 Analogue Scale (0: no pain,1: mild pain, 2: moderate pain 3: severe pain) with a mean value

9 of $[$ mean \pm SE] $1.88 \pm 0.078$.

10 The remaining 20 of the 35 volunteers were used as controls since they suffered from

11 migraine or tension type headache no more than 1-2 times a year.

12 The study was approved by the institutional review board (Ethical Committee of the 13 Fondazione IRCCS Istituto Neurologico Nazionale Casimiro Mondino, date of approval: July $1429^{\text {th }} 2013$ ) and conformed with the Declaration of Helsinki. All patients signed written 15 informed consent before participating to the study.

16 Frontal Infrared Thermography

17 FIT was assessed with a modern infrared thermal camera (model LT3, produced by Zhejiang 18 Dali Technology Co. Ldt) characterized by a thermal sensitivity below $0.08^{\circ} \mathrm{C}$ at $30^{\circ} \mathrm{C}$, 19 according to suggested guidelines ${ }^{12,13}$. FIT measured the spatial distribution of the heat over 20 the human face (object emissivity 0.98): the camera was placed at distance of 1 meter from 21 the subject in a room with stable temperature $\left(23.6 \pm 1.57^{\circ} \mathrm{C}\right)$. To ensure comparability 22 between patients and controls, since controls do not have a "cold area", the temperature was 23 evaluated in two target points (left and right side) in the frontal polar sites. In patients, we 24 identified the coolest point in the side showing the cold patch, and then we identified its 25 symmetric on the other side of the head (equidistant from the nasion, Fig.1). In controls there 
1 is no cold patch, so we used two symmetric points equidistant from the nasion on a radius of

$22 \mathrm{~cm}$ (Fig.2). This protocol allowed repeatability and comparability among subjects.

\section{Study design}

4 All measurements were taken in two test sessions (T1 and T2) for all subjects. The second 5 session (T2) was run at least one day apart in order to evaluate the intra-subject variations in

6 FIT. During each session (T1 and T2), the measurements were repeated three times (m1, $\mathrm{m} 2$, $7 \mathrm{~m} 3$ ) by the same experimenter after 10 minutes of rest between each measurement. Room

8 temperature was recorded during each session. Images where taken approximately at the same 9 time of the day in each patient (10-12 a.m. or 2.00-4.00 p.m.).

10

11

12

\section{Data analysis}

Reliability of Frontal Thermography (FIT)

In order to verify whether measurements were influenced by external factors, correlation analysis was computed with respect to room temperature, sex and age of subjects, both at T1 and at $\mathrm{T} 2$, using $\mathrm{m} 1, \mathrm{~m} 2$, and $\mathrm{m} 3$ as dependent variables.

Student's paired t-Test was used to determine whether three measurements belonging to the same session ( $\mathrm{m} 1$ vs $\mathrm{m} 2, \mathrm{~m} 2$ vs $\mathrm{m} 3, \mathrm{~m} 1$ vs $\mathrm{m} 3$ ) had the same mean. The Bonferroni correction for repeated measures was applied $(\mathrm{p}<0.016)$.

Reliability of measurements was investigated using the intra-class correlation coefficient (ICC), defined as the fraction of variance that is caused by the variation between subjects. Thus, if the variance between tests is smaller than the variance between subjects then ICC is close to 1. According to Fleiss, ICC values above 0.75 generally mean "excellent" reliability ${ }^{14}$. The intra-class correlation coefficient (ICC) was calculated for FIT at each point: data during a single session (T1 and T2) were analysed using a Two Factor ANOVA without 
1 Replication (factors: subjects and FIT readings $\mathrm{m}_{\mathrm{i}}$ ) and the value from the analysis of variance

2 table were substituted into equation (1):

$3 \quad \mathrm{ICC} 2,1=(\mathrm{BMS}-\mathrm{EMS}) /(\mathrm{BMS}+\mathrm{EMS}+2(\mathrm{JMS}-\mathrm{EMS}) / \mathrm{n})$

4 where BMS is the between-subjects mean square, EMS is the residual mean square, JMS is

5 the within-subjects mean square, $\mathrm{n}$ is number of subjects ${ }^{15}$.

6 The reproducibility of the method was tested by calculating the Coefficient of Variation (CV)

7 during the first test session ${ }^{16,17}$. For each comparison between measurements ( $\mathrm{m} 1 \mathrm{vs} \mathrm{m} 2, \mathrm{~m} 2$

8 vs $\mathrm{m} 3, \mathrm{~m} 1$ vs $\mathrm{m} 3$ ) the coefficient of variation (equation 2) was calculated as the absolute

9 value of:

$10 \mathrm{CV}=100^{*}\left|\left(\mathrm{~m}_{\mathrm{i}}-\mathrm{m}_{\mathrm{i}+1}\right) /\left(\left(\mathrm{m}_{\mathrm{i}}+\mathrm{m}_{\mathrm{i}+1}\right) / 2\right)\right|$

11 where $m_{i}$ is the first reading (test) and $m_{i+1}$ is the second one (retest). The numerator is the

12 difference between two consecutive measurements and the denominator is the average of the

13 two measurements. In this way, the Coefficient of Variation is the percentage difference

14 between two readings. For each subject the coefficient of variation was computed for the three

15 intra-session comparisons and then averaged across subjects.

16 In order to evaluate the intra-subject variations in FIT, a two-way analysis of variance with

17 replication (2-way ANOVA) was performed for a statistical comparison between two

18 different test sessions (T1 and T2).

19 Characterization of images comparing controls and patients

20 In order to verify the difference between migraine FIT measurement and healthy subject FIT

21 measurements, we defined two parameters:

22 - the Asymmetry Index [14] (equation 3)

$23 \quad \mathrm{AI}=2 \times(($ Tleft-Tright $) /($ Tleft + Tright $))$

24 Where Tleft is the temperature on the left forehead and Tright is the temperature of the right

25 forehead. AI was calculated in order to assess the lateralization of FIT. If the temperature 
1 measurement on the two sides is the same, then the asymmetry index is equal to 0 . Positive AI

2 value means that the cold patch is located on the right side of the forehead. Conversely, a

3 negative asymmetry index means a lateralization on the left side.

- the absolute value of percentage difference between left and right side

$5 \quad$ Side Difference $(\%)=100 * \mid 2 *($ Tleft - Tright $/$ Tleft + Tright $) \mid$

6 SideDifference (equation 4) is the difference between left and right side as a percentage of the

7 average temperature in forehead.

8 Both parameters were calculated from all the measurements of each patients $\left(15^{*} 6=90\right.$

9 observations) and controls ( $20 * 6=120$ observations). A comparison between the two groups

10

11

12 was conducted in order to test whether there was a significant difference of AI or Side Difference. In headache patients, the Asymmetry Index was compared with FIT visual inspection by the doctor and with declarations of patient before each session (the side of pain and intensity of pain using VAS scores).

\section{Results}

\section{Reliability of frontal infrared thermography}

FIT readings did not correlate with external factors during both during $\mathrm{T} 1$ and $\mathrm{T} 2$ sessions as far as sex (Tright $\mathrm{r}=0.20, \mathrm{p}=0.24$; Tleft $\mathrm{r}=0.23, \mathrm{p}=0.17$ ), room temperature (Tright $\mathrm{r}=$ $0.22, p=0.20 ;$ Tleft $r=0.19, p=0.27)$ and age (Tright $r=-0.017, p=0.92 ;$ Tleft $r=0.035, p$ $=0.83)$ is concerned.

During each session, paired t-Test analysis revealed no significant difference between consecutive FIT measurements during the same session $(\mathrm{p}>0.016)$ for all the three comparisons ( $\mathrm{m} 1 \mathrm{vs} \mathrm{m} 2, \mathrm{~m} 2$ vs $\mathrm{m} 3, \mathrm{~m} 1 \mathrm{vs} \mathrm{m} 3$ ) in both the right and left measurement side (Figure 3). 
1 The reliability analysis demonstrated "excellent" ${ }^{\text {"14 }}$ results during T1 (ICC values: right side,

20.73 ; left side, 0.81). The same result was confirmed during T2 (ICC values: right side, 0.80;

3 left side, 0.74).

4 Regarding the reproducibility, mean CV between consecutive FIT measurements in the right

5 and left side were similar in controls (T1: left side: $1.63 \% \pm 1.79$; right side: $1.69 \% \pm 2.09$;

6 T2: left side: $2.71 \% \pm 3.26$; right side: $2.67 \% \pm 3.22$ ) and in patients (T1: left side: $3.77 \% \pm$

7 3.57; right side: $3.87 \% \pm 3.62$; T2: left side: $2.71 \% \pm 3.26$; right side: $2.67 \% \pm 3.22$ ).

8 However, in patients, CV range was slightly greater than in controls both in $\mathrm{T} 1$ and $\mathrm{T} 2$

9 session (patients: $0.00 \%-13.40 \%$; controls: $0.00 \%-10.04 \%$ ). In addition, the average smallest

$10 \mathrm{CV}$ was observed among $\mathrm{m} 2 \mathrm{~m} 3$ measurements $(\mathrm{m} 2 \mathrm{~m} 3: 1.56 \% \pm 0.62 \mathrm{vs} \mathrm{m} 1 \mathrm{~m} 2: 3.13 \% \pm 1.29$

11 and $\mathrm{m} 1 \mathrm{~m} 3: 3.54 \% \pm 1.25)$. Despite this, the overall reproducibility of the measurements was

12 very good because the maximum CV was less than $13.40 \%$.

13 When examining intra-subject variations between two different days (inter-test), CV 14 represents the percentage difference between two daily sessions ( $\mathrm{T} 1$ and $\mathrm{T} 2$ ). The maximum 15 CVs between test sessions (T1 and T2) were very low (patients range: $0.19-8.24 \%$, controls 16 range: $0.00-7.56 \%$ ) thus suggesting a good reproducibility of the measurements over 17 different days.

18 The range of temperature was not different between days or between the two groups of 19 subjects (controls: T1: $33.10-36.73^{\circ} \mathrm{C}$; T2: $34.13-36.70^{\circ} \mathrm{C}$; patients: T1: $32.30-37.60$; T2: $2032.30-36.17^{\circ} \mathrm{C}$ ). Patients were characterized by a larger standard deviation of temperature 21 than controls (Figure 3). The two-way ANOVA with replication over 35 subjects 22 demonstrated that there were no significant differences between FIT measurements in 23 different days.

24 Characterization of frontal infrared thermography comparing patients and controls 
1 In controls, the temperature measurements during $\mathrm{T} 1$ varied from a minimum of $32.60^{\circ} \mathrm{C}$ to a

2 maximum value of $38.90^{\circ} \mathrm{C}$ (mean on the two sides: $35.05^{\circ} \mathrm{C}$, standard deviation: $1{ }^{\circ} \mathrm{C}$,

3 corresponding to $2.8 \%$ of the mean value). In patients with chronic migraine the temperature

4 measurements during T1 varied from a minimum of $31.90^{\circ} \mathrm{C}$ to a maximum value of $38.30^{\circ} \mathrm{C}$

5 with a larger standard deviation from the mean than controls (mean on the two sides $35.47^{\circ} \mathrm{C}$,

6 standard deviation $1.59^{\circ} \mathrm{C}$, corresponding $4.5 \%$ of the mean value).

7 Whereas average AI was not different $(\mathrm{p}>0.05)$ between patients $(-0.00002 \pm 0.0164)$ and

8 controls $(-0.00118 \pm 0.0091)$, the Side Difference, representing the absolute value of the

9 difference between temperature measured in the left and right side, significantly discriminated 10 controls (mean \pm std: $0.73 \% \pm 0.55)$ from patients ([mean $\pm \mathrm{SD}]: 1.37 \% \pm 0.87, \mathrm{P}$-value one 11 tail<0.0001) (Fig. 4).

12 Conversely, AI can be used to locate the cold patch in patients. In fact, AI polarity (positive or 13 negative, where positive AI value means that the cold patch is located on the right side of the 14 forehead) was in consort with the visual inspection of the FIT by the examiner (correlation, $15 \mathrm{r}^{2}=0.7, \mathrm{p}=0.00072$ ). In addition, when the patient referred a bilateral pain before the test 16 session, both the visual inspection and the AI index revealed an asymmetry in the forehead, 17 thus suggesting that the AI can be a reliable index for the localization of the coldpatch also 18 when the patient's perception is not reliable.

19 Finally, in patients with unilateral pain, the correlation between AI and the patient-referred 20 pain side before FIT was good $\left(\mathrm{r}^{2}=0.6, \mathrm{p}=0.0056\right)$. Conversely, even though patients were 21 examined mainly during attacks with different pain severities, as measured by VAS, the 22 correlation between $\mathrm{AI}$ and pain severity was very low $\left(\mathrm{r}^{2}=0.2, \mathrm{p}=0.37\right)$.

\section{Discussion}


1 In this study, we examined the usability and reproducibility of FIT measurement in patients

2 with headache and in healthy subjects, in a research scenario in which previous experience

3 using FIT were not conclusive ${ }^{1,3,4,6,7,18}$.

4 In order to obtain comparable results between patients and controls, we used a thermal

5 punctual evaluation instead of an evaluation by area. In fact, whereas patients showed a cooler

6 area (the cold patch), controls did not, thus making the evaluation by area unreliable and not

7 reproducible. We therefore chose to evaluate the temperature in two symmetric points

8 equidistant from the nasion. In patients, one point was the coolest point in the cold patch, and

9 the second was its symmetric, in controls we took two symmetric points located on a circle of

10 fixed radius. With this setup, our data showed that FIT is a reproducible tool provided that

11 standard location and standard measurement procedure is carried out. In fact, we found good

12 reproducibility of the measurements within the same session and between the two sessions, as

13 measured by CV. However, we also found the smallest CV in the comparison between the

14 second reading and the third reading during each test sessions, while the first reading, even

15 though statistically not different from the others, cannot be always reliable during

16 thermography. Since the first reading was taken immediately when the patient entered the

17 room, it is likely that, after some minutes, there is some stabilization of the subject at the

18 room temperature that affects the absolute measurements. This observation suggests that a

19 stabilization period of the subject at the room temperature is recommended before the

20 thermograph exam in order to guarantee an effective measurement. This is in line with

21 available guidelines suggesting that thermography measures should be taken after a

22 stabilization period of 15-20 minutes to allow equilibrating with the environment. ${ }^{12,13}$

23 Our data also suggest that FIT is a reliable procedure in detecting the cold patch location in

24 headache patients and that the AI parameter is able to localize the cold patch even when the

25 patient referred a bilateral pain before the image is recorded. In previous studies, no 
1 correlation was found between FIT measurements and pain side or VAS score in patients ${ }^{5,18}$.

2 Instead, our results demonstrate that the Asymmetry Index defined by Kurth et al. ${ }^{19}$ well

3 describe the lateralization of cold patch in patients. Moreover, AI index correlates with

4 doctor's visual inspection of FIT and in case of unilateral pain there is a good correlation

5 between AI and pain side. Even if the correlation between AI and VAS score is low, AI index

6 could be a useful tool in order to localize the pathological side (where there is the coldpatch)

7 in each patient. Our results further confirm that regardless to patient's perception, the cold

8 patch can be viewed as a "unilateral" entity, representing the neurochemical imbalance

9 between the two sides in terms of microcirculation in the facial district. This hypothesis is in 10 line with neurophysiological studies on Visual Evoked Potentials showing a prominent 11 laterality of neurophysiological signatures in headache ${ }^{20-24}$. Therefore, the AI estimated by

12 FIT can have a relevant prognostic role going beyond patient's perception.

13 Finally, the SideDifference parameter was able to discriminate headache patients from 14 controls, even if the FIT image was taken with patients experiencing different pain intensities.

15 These observations suggest that FIT can be a useful neurophysiological aid in the diagnosis 16 for pain medicine. An add-on marker in diagnosis may be useful in difficult case or when 17 there is a risk for diagnostic mistakes concerning unilateral or bilateral headaches form ${ }^{26}$. We 18 foresee the time when FIT could be used in evaluating pharmacological and non19 pharmacological treatment in headache and other facial neuralgia: FIT with a commercially 20 available camera is a relatively inexpensive procedure that can be used in headache and pain 21 centre setting.

22 However, even though promising, our results were obtained in a relatively small number of 23 subjects, and acquisitions followed a shared protocol that guaranteed consistency across 24 subjects. Therefore, for future applications, it will be important to create a consensus 25 procedure for FIT acquisition, able to support diagnosis. 
1 From a practical viewpoint, in the current therapeutic scenario, where non-invasive

2 neuromodulation techniques are increasingly used for the treatment of migraine [21-23][25-

3 27] , these results can reach an even more interesting meaning. In fact, transcranial direct 4 current stimulation (tDCS) has been proposed for the treatment of migraine ${ }^{27,28,30,31}$. tDCS is

5 a non-invasive technique that acts sub-threshold $(<1 \mathrm{~V} / \mathrm{m}$ vs. $100 \mathrm{~V} / \mathrm{m}$ produced by other

6 supra-threshold techniques ${ }^{32}$, producing an excitability change in the area below the electrode.

7 Even though the electric field induced by tDCS spread over neighbouring areas, the electrode

8 montage is a crucial element in the optimization of tDCS therapy ${ }^{29}$. In migraine, electrodes

9 are usually placed in the frontal area, according to patient's perception and subjective

10 analysis. Conversely, the cold patch, representing a vasoconstriction area characterizing the

11 migraine may be an effective target for neuromodulation intervention. In migraine patients,

12 the cold patch corresponds to a vasoconstriction within the external carotid territory, which

13 represents the end result of the haemodynamic changes due to the activity of the autonomic

14 and the trigeminovascular systems. In this case, cathodal tDCS over this area may reduce the

15 pathological frontal asymmetry. For this reason, the automatic localization of cold patch using

16 FIT based parameters, as proposed in this study, can be applied for the optimization of tDCS

17 treatment in migraine patients.

18 Taken together, our results suggest that FIT could be useful as a diagnostic tool, to localize 19 the cold patch and to study of unilateral headache without side shift like Cluster Headache, 20 Paroxysmal Hemicrania, SUNCT or cranial neuralgias (trigeminal neuralgia). However, the 21 case series is relatively small in order to evaluate the sensitivity and specificity of FIT in 22 discriminating between different headache entities. In addition, even though at present there is 23 no strong evidence supporting the change of FIT after a pharmacological or non24 pharmacological treatment, the use tDCS or prophylactic agents (beta blockers, Calcium 
1 antagonist ) show a tendency to reducing or disappearing of FIT asymmetry, thus suggesting

2 the use of FIT also as a prognostic tool.

3

\section{Conclusions}

5 In conclusion, in respect to previous studies, this work introduces the possibility to use

6 modern commercial infrared thermal camera for the analysis of frontal thermography in

7 migraine patients. Moreover, two new parameters (AI and Side Difference) provided

8 meaningful results, being one able to localize the cold patch and the other one able to 9 distinguish patients from controls.

10

11

12

\section{Article Highlights}

- The use of Frontal Infrared Thermography (FIT) in the diagnosis of primary headaches is still debated.

- In this study, we showed that FIT measurements have good reproducibility even when using commercial cameras in both patients and controls.

- We defined a new parameter, the Side Difference, that is able to discriminate patients with headache from controls.

- We defined another parameter, the Asimmetry Index, that correlates with the side of pain.

- FIT can be used to characterize vascular changes in chronic migraine patients but standardized recording conditions are needed to guarantee reliability. 


\section{Funding resources}

2 This research did not receive any specific grant from funding agencies in the public,

3 commercial, or not-for-profit sectors.

4

\section{Institutional Review Board Approval:}

6 The study was approved by the institutional review board (Ethical Committee of the 7 Fondazione IRCCS Istituto Neurologico Nazionale Casimiro Mondino, date of approval: July $829^{\text {th }}$ 2013) and conformed with the Declaration of Helsinki. All patients signed written 9 informed consent before participating to the study.

10

\section{Conflict of interest statement}

12 Elena Rossi, at the time of the work, was employed by Newronika Srl, a spin-off company of 13 the Fondazione IRCCS Ca' Granda Ospedale Maggiore Policlinico and of the University of 14 Milan. Sara Marceglia is founder and shareholder of Newronika Srl.

15 The other authors declare no conflict. 
1 References

2 1. Szentkuti A, Kavanagh HS, Grazio S. Infrared thermography and image analysis for biomedical use. Period Biol 2011; 113: 385-392.

2. Haddad DS, Brioschi ML, Baladi MG, et al. A new evaluation of heat distribution on facial skin surface by infrared thermography. Dentomaxillofacial Radiol 2016; 45: 20150264.

3. Swerdlow B, Dieter JN. The Validity of the Vascular 'Cold Patch' in the Diagnosis of Chronic Headache. Headache J Head Face Pain 1986; 26: 22-26.

4. Edmeads J. Is thermography a marker for vascular headaches? Headache 1986; 26: 47.

5. Swerdlow B, Dieter JN. The vascular 'cold patch' is not a prognostic index for headache. Headache 1989; 29: 562-568.

6. Dalla Volta G, Anzola GP. Are There Objective Criteria to Follow Up Migrainous Patients? A Prospective Study with Thermography and Evoked Potentials. Headache J Head Face Pain 1988; 28: 423-425.

7. Dalla Volta G, Anzola GP, DiMonda V. The disappearance of the 'cold patch' in recovered migraine patients: thermographic findings. Headache 1991; 31: 305-309.

8. Drummond PD, Lance JW. Facial temperature in migraine, tension-vascular and tension headache. Cephalalgia Int J Headache 1984; 4: 149-158.

9. Drummond PD, Lance JW. Thermographic changes in cluster headache. Neurology 1984; 34: 1292-1298.

10. Zaproudina N, Närhi M, Lipponen JA, et al. Nitroglycerin-induced changes in facial skin temperature: 'cold nose' as a predictor of headache? Clin Physiol Funct Imaging 2013; n/a-n/a.

11. Headache Classification Committee of the International Headache Society (IHS). The International Classification of Headache Disorders, 3rd edition (beta version).

Cephalalgia Int J Headache 2013; 33: 629-808.

12. American Academy of Thermology. Guidelines for neuro-musculoskeletal infrared medical thermography and sympathetic skin response (SSR) studies, https://aathermology.org/organization-2/guidelines/guidelines-for-neuromusculoskeletal-thermography/ (accessed 12 June 2018).

13. Schwartz RG, Getson P, O’Young B, et al. Guidelines for Dental-Oral and Systemic Health Infrared Thermography. Pan Am J Med Thermol 2015; 2: 44-53.

14. Fleiss JL. The Design and Analysis of Clinical Experiments: Fleiss/The Design. Hoboken, NJ, USA: John Wiley \& Sons, Inc. Epub ahead of print 8 February 1999. DOI: $10.1002 / 9781118032923$.

15. Lexell JE, Downham DY. How to assess the reliability of measurements in rehabilitation. Am J Phys Med Rehabil 2005; 84: 719-723. 
1 16. Antonaci F, Sand T, Lucas GA. Pressure algometry in healthy subjects: inter-examiner variability. Scand J Rehabil Med 1998; 30: 3-8

17. Shrout PE, Fleiss JL. Intraclass correlations: uses in assessing rater reliability. Psychol Bull 1979; 86: 420-428.

18. Ford R, Ford K. Thermography in the Diagnosis of Headache. Semin Neurol 1997; 17: 343-349.

19. Kurth F, Gaser C, Luders E. A 12-step user guide for analyzing voxel-wise gray matter asymmetries in statistical parametric mapping (SPM). Nat Protoc 2015; 10: 293-304.

20. Anzola GP, Dalla Volta G, Di Monda V, et al. Laterality Indexes In Primary Headache : Teletermography, Visual Evoked Potentials, Reaction Times. Cephalalgia 1987; 7: 301301.

21. Kudrow L. Thermographic and Doppler Flow Asymmetry in Cluster Headache. Headache J Head Face Pain 1979; 19: 204-208.

22. Gawel M, Connolly JF, Rose FC. Migraine Patients Exhibit Abnormalities in the Visual Evoked Potential. Headache J Head Face Pain 1983; 23: 49-52.

23. Raudino F. Visual evoked potential in patients with migraine. Headache 1988; 28: 531533.

24. Boylu E, Domaç FM, Koçer A, et al. Visual evoked potential abnormalities in migraine patients. Electromyogr Clin Neurophysiol 2010; 50: 303-308.

25. Drummond PD. Vascular Changes in Atypical Facial Pain. Headache J Head Face Pain 1988; 28: 121-123.

26. Voiticovschi-Iosob C, Allena M, De Cillis I, et al. Diagnostic and therapeutic errors in cluster headache: a hospital-based study. J Headache Pain 2014; 15: 56.

27. Antal A, Kriener N, Lang N, et al. Cathodal transcranial direct current stimulation of the visual cortex in the prophylactic treatment of migraine. Cephalalgia Int J Headache $2011 ; 31: 820-828$.

28. Dasilva AF, Mendonca ME, Zaghi S, et al. tDCS-induced analgesia and electrical fields in pain-related neural networks in chronic migraine. Headache 2012; 52: 1283-1295.

29. DaSilva AF, Truong DQ, DosSantos MF, et al. State-of-art neuroanatomical target analysis of high-definition and conventional tDCS montages used for migraine and pain control. Front Neuroanat 2015; 9: 89.

30. Magis D. Neuromodulation in migraine: state of the art and perspectives. Expert Rev Med Devices 2015; 12: 329-339.

31. Viganò A, D'Elia TS, Sava SL, et al. Transcranial Direct Current Stimulation (tDCS) of the visual cortex: a proof-of-concept study based on interictal electrophysiological abnormalities in migraine. $J$ Headache Pain 2013; 14: 23. 
1

2

3

4

5

6

7

8

9

10

32. Dmochowski JP, Datta A, Bikson M, et al. Optimized multi-electrode stimulation increases focality and intensity at target. J Neural Eng 2011; 8: 046011.

\section{$3 \quad$ Figures legends}

4 Figure 1- Measurement point identification in patients. The radius of the circle was calculated 5 as the distance between the Nasion and the coolest point in the cold patch. Once defined the

6 radius, the second point was the point equidistant from the Nasion and with the same vertical

7 coordinate of the first point of measurement (symmetric point).

8

9 Figure 2- Measurement point identification in controls. The radius of the circle was constant.

10

11 Figure 3 - Mean FIT measured over 20 controls (left side) and 15 patients (right side) in 12 three consecutive readings ( $\mathrm{m} 1, \mathrm{~m} 2, \mathrm{~m} 3$ - $\mathrm{x}$ axis) with 10 minutes of rest between readings 13 during T1 and T2. Error bars represent standard errors.

14

15 Figure 4 - Difference between left and right side as a percentage of the average temperature 16 in forehead (SideDifference) in patients $(\mathrm{N}=20)$ and controls $(\mathrm{N}=15)$. 


\section{Frontal infrared thermography in healthy individuals and chronic \\ 2 \\ migraine patients: reliability of the method}

3

4 Fabio Antonaci, $\mathrm{MD}, \mathrm{PhD}^{1}$, Elena Rossi, $\mathrm{PhD}^{2,3}$, Cristina Voiticovschi-Iosob, $\mathrm{MD}^{4}$, Giorgio

5

6

7

8

9

10

11

12

13

14 15

16

17

18

19

20

21

22

23

24

25

26

27

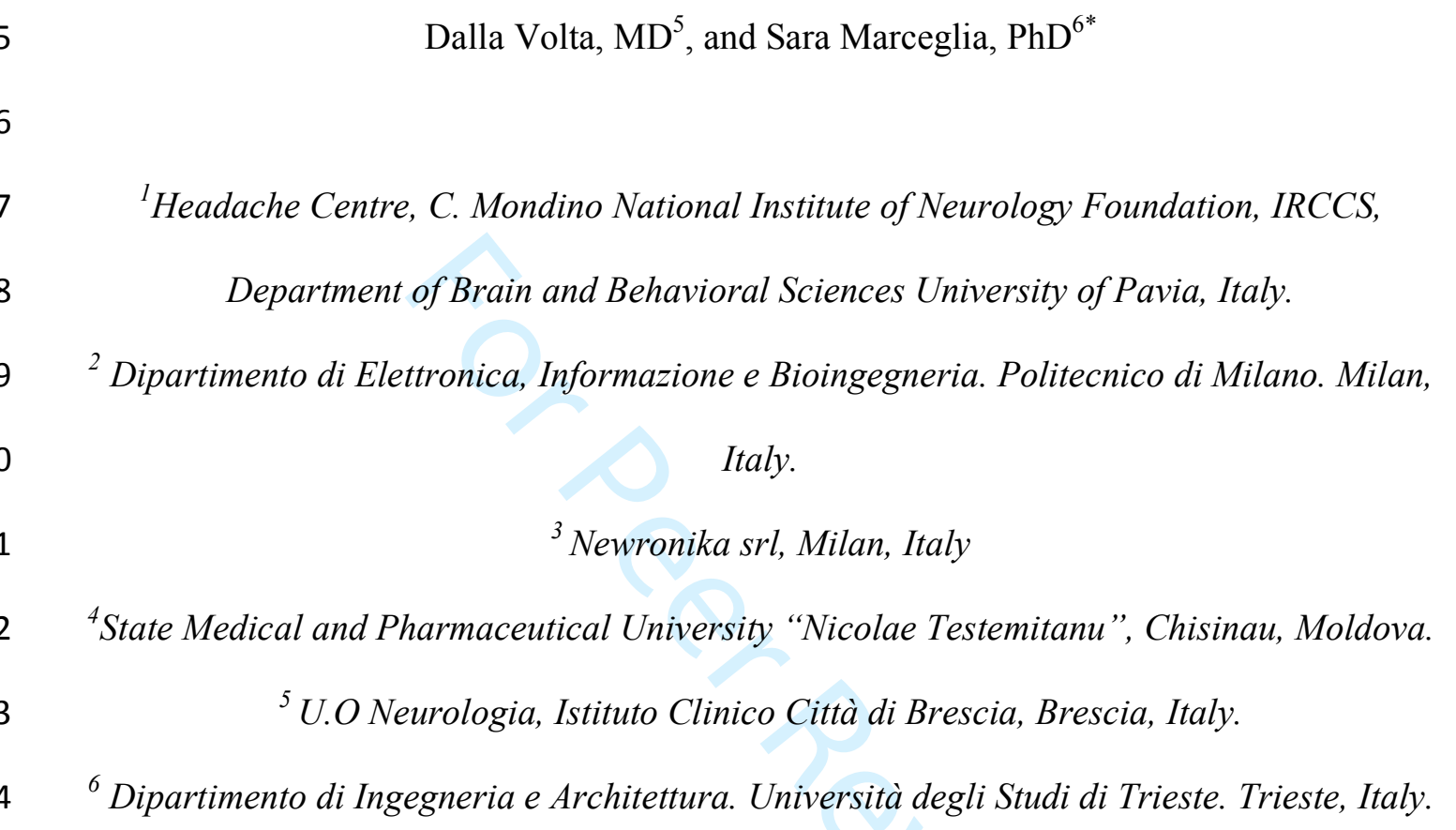




\author{
1 Abbreviations \\ 2 AI - Asymmetry Index \\ 3 ANOVA - analysis of variance \\ 4 BMS - between-subjects mean square \\ 5 CV - Coefficient of Variation \\ 6 EMS - residual mean square \\ $7 \quad$ FIT - Frontal Infrared Thermography \\ 8 ICC - intra-class correlation coefficient \\ 9 JMS - within-subjects mean square \\ 10 tDCS - transcranial direct current stimulation \\ 11 VAS - Visual Analogue Scale \\ 12
}

13

14 


\section{$1 \quad \underline{\text { Abstract }}$}

2 Background: The use of Frontal infrared thermography in the diagnosis of primary

3 headaches provided scattering results due to measurement fluctuations and different types of

4 headaches or research protocols.

5 Objective: This study aims to assess the reliability of Frontal infrared thermography in

6 healthy individuals and provide a preliminary evaluation in chronic migraine patients using a

7 commercial infrared thermal camera.

8 Methods: Thermographic images were acquired in 20 controls and 15 patients at 3 9 consecutive time-points in two daily sessions. The Side Difference and Asymmetry Index 10 parameters were defined. The reproducibility of the measurements, the correlation of 11 Asymmetry Index and Side Difference with clinical evaluations and patient perceptions, and 12 the ability of the parameters to discriminate between patients and controls were investigated.

13 Results: We reported a good reproducibility of the measurements (Inter-class Correlation 14 Coefficient $>0.75$ and Coefficient of Variation $<13.4 \%$ ), independent from external factors. 15 The Side Difference was significantly different between patients and controls $(p<0.001)$. The 16 Asymmetry Index showed good correlation with the side of unilateral pain $(\mathrm{p}=0.0056)$.

17 Conclusions: Frontal infrared thermography can be used to quantify the difference between 18 the right and the left side of frontal vascular changes in chronic migraine patients, provided 19 that standardized conditions are satisfied. 
1 Anyway, there is large consensus on the fact that the cold patch represents an asymmetry in

2 the forehead of migraine patients. Unfortunately, the location of the cold patch is seldom

3 related to the side of the pain ${ }^{5}$ probably due to the variation of temperature during headache

4 attack or due to the lateralization of the headache (unilateral or bilateral) as measured by

5 Drummond and Lance ${ }^{8,9}$.

6 Finally, FIT, in conjunction with nitroglycerine administration, was suggested as a novel non-

7 invasive approach to study vascular processes underlying headaches ${ }^{10}$.

8 Taken together, all these studies demonstrate that FIT can be used as diagnostic tool in

9 migraine with and without aura, in cluster headache and in other headache types.

10 In the light of previous observations and of new possible therapeutic applications, the present

11 study has two primary end points: (1) to evaluate the reliability of FIT measurements in

12 controls and chronic migraine patients using modern commercial infrared thermal camera; (2)

13 to verify whether FIT-based parameters correlate both with the visual evaluation of FIT by an

14 expert clinician and with patient's perception of pain side (at least in case of unilateral pain).

15

16 Materials and methods

\section{Subjects}

18 Thirty five right handed volunteers (26 females and 9 males) with a mean age of $35 \pm 11.6$ 19 years (range: 20-55) were enrolled at the Headache centre of the Fondazione IRCCS Istituto 20 Neurologico Nazionale Casimiro Mondino. All the subjects were not medicated at the time of 21 testing.

2215 of the 35 volunteers ( 3 males) suffered from chronic migraine with medication overuse, as 23 assessed according to the IHS Classification ${ }^{11}$. They were examined while hospitalized and 24 during a washout period from analgesics or other symptomatic treatment, including non25 headache medication. Patients were not on dietary/smoking restrictions ahead of 
1 measurements. Patients did not use preventive treatment and underwent daily parenteral

2 detoxification (saline, cyanocobalamin, folic acid, nicotinammide, glutathione, delorazepam

3 and metoclopramide on demand). Patients were assessed on the second or third day after

4 symptomatic medication withdrawal that started on the day of hospital admission. No

5 symptomatic medication was allowed during the evaluation period but local ice bag (at least

6 one day apart from the examination). Hence, patients were generally with headache during the

7 examination. Pain severity was evaluated before each examination on a $0-3$-score Visual

8 Analogue Scale (0: no pain,1: mild pain, 2: moderate pain 3: severe pain) with a mean value

9 of $[$ mean \pm SE] $1.88 \pm 0.078$.

10 The remaining 20 of the 35 volunteers were used as controls since they suffered from

11 migraine or tension type headache no more than 1-2 times a year.

12 The study was approved by the institutional review board (Ethical Committee of the 13 Fondazione IRCCS Istituto Neurologico Nazionale Casimiro Mondino, date of approval: July $1429^{\text {th }}$ 2013) and conformed with the Declaration of Helsinki. All patients signed written 15 informed consent before participating to the study.

16 Frontal Infrared Thermography

17 FIT was assessed with a modern infrared thermal camera (model LT3, produced by Zhejiang 18 Dali Technology Co. Ldt) characterized by a thermal sensitivity below $0.08^{\circ} \mathrm{C}$ at $30^{\circ} \mathrm{C}$, 19 according to suggested guidelines ${ }^{12,13}$. FIT measured the spatial distribution of the heat over 20 the human face (object emissivity 0.98): the camera was placed at distance of 1 meter from 21 the subject in a room with stable temperature $\left(23.6 \pm 1.57^{\circ} \mathrm{C}\right)$. To ensure comparability 22 between patients and controls, since controls do not have a "cold area", the temperature was 23 evaluated in two target points (left and right side) in the frontal polar sites. In patients, we 24 identified the coolest point in the side showing the cold patch, and then we identified its 25 symmetric on the other side of the head (equidistant from the nasion, Fig.1). In controls there 
1 is no cold patch, so we used two symmetric points equidistant from the nasion on a radius of

$22 \mathrm{~cm}$ (Fig.2). This protocol allowed repeatability and comparability among subjects.

\section{$3 \quad$ Study design}

4 All measurements were taken in two test sessions (T1 and $\mathrm{T} 2$ ) for all subjects. The second 5 session (T2) was run at least one day apart in order to evaluate the intra-subject variations in

6 FIT. During each session (T1 and T2), the measurements were repeated three times (m1, $\mathrm{m} 2$, $7 \mathrm{~m} 3$ ) by the same experimenter after 10 minutes of rest between each measurement. Room 8 temperature was recorded during each session. Images where taken approximately at the same 9 time of the day in each patient (10-12 a.m. or 2.00-4.00 p.m.).

10

\section{Data analysis}

12 Reliability of Frontal Thermography (FIT)

13 In order to verify whether measurements were influenced by external factors, correlation 14 analysis was computed with respect to room temperature, sex and age of subjects, both at $\mathrm{T} 1$ 15 and at $\mathrm{T} 2$, using $\mathrm{m} 1, \mathrm{~m} 2$, and $\mathrm{m} 3$ as dependent variables.

16 Student's paired t-Test was used to determine whether three measurements belonging to the 17 same session ( $\mathrm{m} 1$ vs $\mathrm{m} 2, \mathrm{~m} 2$ vs $\mathrm{m} 3, \mathrm{~m} 1$ vs $\mathrm{m} 3$ ) had the same mean. The Bonferroni 18 correction for repeated measures was applied $(\mathrm{p}<0.016)$.

19 Reliability of measurements was investigated using the intra-class correlation coefficient 20 (ICC), defined as the fraction of variance that is caused by the variation between subjects. 21 Thus, if the variance between tests is smaller than the variance between subjects then ICC is 22 close to 1. According to Fleiss, ICC values above 0.75 generally mean "excellent" 23 reliability ${ }^{14}$. The intra-class correlation coefficient (ICC) was calculated for FIT at each point: 24 data during a single session (T1 and T2) were analysed using a Two Factor ANOVA without 
1 Replication (factors: subjects and FIT readings $\mathrm{m}_{\mathrm{i}}$ ) and the value from the analysis of variance

2 table were substituted into equation (1):

$3 \quad$ ICC $2,1=(\mathrm{BMS}-\mathrm{EMS}) /(\mathrm{BMS}+\mathrm{EMS}+2(\mathrm{JMS}-\mathrm{EMS}) / \mathrm{n})$

4 where BMS is the between-subjects mean square, EMS is the residual mean square, JMS is

5 the within-subjects mean square, $\mathrm{n}$ is number of subjects ${ }^{15}$.

6 The reproducibility of the method was tested by calculating the Coefficient of Variation (CV)

7 during the first test session ${ }^{16,17}$. For each comparison between measurements ( $\mathrm{m} 1 \mathrm{vs} \mathrm{m} 2, \mathrm{~m} 2$

8 vs $\mathrm{m} 3, \mathrm{~m} 1$ vs $\mathrm{m} 3$ ) the coefficient of variation (equation 2) was calculated as the absolute 9 value of:

$\mathrm{CV}=100 *\left|\left(\mathrm{~m}_{\mathrm{i}}-\mathrm{m}_{\mathrm{i}+1}\right) /\left(\left(\mathrm{m}_{\mathrm{i}}+\mathrm{m}_{\mathrm{i}+1}\right) / 2\right)\right|$

11 where $m_{i}$ is the first reading (test) and $m_{i+1}$ is the second one (retest). The numerator is the 12 difference between two consecutive measurements and the denominator is the average of the 13 two measurements. In this way, the Coefficient of Variation is the percentage difference 14 between two readings. For each subject the coefficient of variation was computed for the three 15 intra-session comparisons and then averaged across subjects.

16 In order to evaluate the intra-subject variations in FIT, a two-way analysis of variance with 17 replication (2-way ANOVA) was performed for a statistical comparison between two 18 different test sessions ( $\mathrm{T} 1$ and $\mathrm{T} 2$ ).

\section{Characterization of images comparing controls and patients}

20 In order to verify the difference between migraine FIT measurement and healthy subject FIT 21 measurements, we defined two parameters:

- the Asymmetry Index [14] (equation 3)

$$
\mathrm{AI}=2 \times((\text { Tleft}- \text { Tright }) /(\text { Tleft }+ \text { Tright }))
$$

24 Where Tleft is the temperature on the left forehead and Tright is the temperature of the right 25 forehead. AI was calculated in order to assess the lateralization of FIT. If the temperature 
1 measurement on the two sides is the same, then the asymmetry index is equal to 0 . Positive AI

2 value means that the cold patch is located on the right side of the forehead. Conversely, a 3 negative asymmetry index means a lateralization on the left side.

4 - the absolute value of percentage difference between left and right side

$5 \quad$ Side Difference $(\%)=100 * \mid 2 *($ Tleft - Tright $/$ Tleft + Tright $) \mid$

6 SideDifference (equation 4) is the difference between left and right side as a percentage of the 7 average temperature in forehead.

8 Both parameters were calculated from all the measurements of each patients $\left(15^{*} 6=90\right.$ 9 observations) and controls ( $20 * 6=120$ observations). A comparison between the two groups 10 was conducted in order to test whether there was a significant difference of AI or Side 11 Difference. In headache patients, the Asymmetry Index was compared with FIT visual 12 inspection by the doctor and with declarations of patient before each session (the side of pain 13 and intensity of pain using VAS scores).

14 15 16 17 18 19 20 $21=0.83)$ is concerned.

22 During each session, paired t-Test analysis revealed no significant difference between 23 consecutive FIT measurements during the same session $(p>0.016)$ for all the three 24 comparisons ( $\mathrm{m} 1$ vs $\mathrm{m} 2, \mathrm{~m} 2$ vs $\mathrm{m} 3, \mathrm{~m} 1 \mathrm{vs} \mathrm{m} 3$ ) in both the right and left measurement side 25 (Figure 3). 
1 The reliability analysis demonstrated "excellent" ${ }^{\text {"14 }}$ results during T1 (ICC values: right side,

2 0.73; left side, 0.81). The same result was confirmed during T2 (ICC values: right side, 0.80;

3 left side, 0.74).

4 Regarding the reproducibility, mean CV between consecutive FIT measurements in the right

5 and left side were similar in controls (T1: left side: $1.63 \% \pm 1.79$; right side: $1.69 \% \pm 2.09$;

6 T2: left side: $2.71 \% \pm 3.26$; right side: $2.67 \% \pm 3.22$ ) and in patients (T1: left side: $3.77 \% \pm$

7 3.57; right side: $3.87 \% \pm 3.62$; T2: left side: $2.71 \% \pm 3.26$; right side: $2.67 \% \pm 3.22$ ).

8 However, in patients, CV range was slightly greater than in controls both in $\mathrm{T} 1$ and $\mathrm{T} 2$

9 session (patients: $0.00 \%-13.40 \%$; controls: $0.00 \%-10.04 \%$ ). In addition, the average smallest

$10 \mathrm{CV}$ was observed among $\mathrm{m} 2 \mathrm{~m} 3$ measurements $(\mathrm{m} 2 \mathrm{~m} 3: 1.56 \% \pm 0.62 \mathrm{vs} \mathrm{m} 1 \mathrm{~m} 2: 3.13 \% \pm 1.29$

11 and $\mathrm{m} 1 \mathrm{~m} 3: 3.54 \% \pm 1.25)$. Despite this, the overall reproducibility of the measurements was

12 very good because the maximum CV was less than $13.40 \%$.

13 When examining intra-subject variations between two different days (inter-test), CV 14 represents the percentage difference between two daily sessions ( $\mathrm{T} 1$ and $\mathrm{T} 2$ ). The maximum 15 CVs between test sessions (T1 and T2) were very low (patients range: $0.19-8.24 \%$, controls 16 range: $0.00-7.56 \%$ ) thus suggesting a good reproducibility of the measurements over 17 different days.

18 The range of temperature was not different between days or between the two groups of 19 subjects (controls: T1: $33.10-36.73^{\circ} \mathrm{C}$; T2: $34.13-36.70^{\circ} \mathrm{C}$; patients: T1: $32.30-37.60$; T2: $2032.30-36.17^{\circ} \mathrm{C}$ ). Patients were characterized by a larger standard deviation of temperature 21 than controls (Figure 3). The two-way ANOVA with replication over 35 subjects 22 demonstrated that there were no significant differences between FIT measurements in 23 different days.

\section{Characterization of frontal infrared thermography comparing patients and controls}


1 In controls, the temperature measurements during $\mathrm{T} 1$ varied from a minimum of $32.60^{\circ} \mathrm{C}$ to a

2 maximum value of $38.90^{\circ} \mathrm{C}$ (mean on the two sides: $35.05^{\circ} \mathrm{C}$, standard deviation: $1{ }^{\circ} \mathrm{C}$,

3 corresponding to $2.8 \%$ of the mean value). In patients with chronic migraine the temperature

4 measurements during T1 varied from a minimum of $31.90^{\circ} \mathrm{C}$ to a maximum value of $38.30^{\circ} \mathrm{C}$

5 with a larger standard deviation from the mean than controls (mean on the two sides $35.47^{\circ} \mathrm{C}$,

6 standard deviation $1.59^{\circ} \mathrm{C}$, corresponding $4.5 \%$ of the mean value).

7 Whereas average AI was not different $(\mathrm{p}>0.05)$ between patients $(-0.00002 \pm 0.0164)$ and

8 controls $(-0.00118 \pm 0.0091)$, the Side Difference, representing the absolute value of the

9 difference between temperature measured in the left and right side, significantly discriminated

10 controls (mean \pm std: $0.73 \% \pm 0.55)$ from patients ([mean $\pm \mathrm{SD}]: 1.37 \% \pm 0.87, \mathrm{P}$-value one

11 tail<0.0001) (Fig. 4).

12 Conversely, AI can be used to locate the cold patch in patients. In fact, AI polarity (positive or 13 negative, where positive AI value means that the cold patch is located on the right side of the 14 forehead) was in consort with the visual inspection of the FIT by the examiner (correlation, $\left.15 \mathrm{r}^{2}=0.7, \mathrm{p}=0.00072\right)$. In addition, when the patient referred a bilateral pain before the test 16 session, both the visual inspection and the AI index revealed an asymmetry in the forehead, 17 thus suggesting that the AI can be a reliable index for the localization of the coldpatch also 18 when the patient's perception is not reliable.

19 Finally, in patients with unilateral pain, the correlation between AI and the patient-referred 20 pain side before FIT was good $\left(\mathrm{r}^{2}=0.6, \mathrm{p}=0.0056\right)$. Conversely, even though patients were 21 examined mainly during attacks with different pain severities, as measured by VAS, the 22 correlation between $\mathrm{AI}$ and pain severity was very low $\left(\mathrm{r}^{2}=0.2, \mathrm{p}=0.37\right)$.

\section{Discussion}


1 In this study, we examined the usability and reproducibility of FIT measurement in patients

2 with headache and in healthy subjects, in a research scenario in which previous experience

3 using FIT were not conclusive ${ }^{1,3,4,6,7,18}$.

4 In order to obtain comparable results between patients and controls, we used a thermal

5 punctual evaluation instead of an evaluation by area. In fact, whereas patients showed a cooler

6 area (the cold patch), controls did not, thus making the evaluation by area unreliable and not

7 reproducible. We therefore chose to evaluate the temperature in two symmetric points

8 equidistant from the nasion. In patients, one point was the coolest point in the cold patch, and

9 the second was its symmetric, in controls we took two symmetric points located on a circle of 10 fixed radius. With this setup, our data showed that FIT is a reproducible tool provided that 11 standard location and standard measurement procedure is carried out. In fact, we found good 12 reproducibility of the measurements within the same session and between the two sessions, as 13 measured by CV. However, we also found the smallest CV in the comparison between the 14 second reading and the third reading during each test sessions, while the first reading, even 15 though statistically not different from the others, cannot be always reliable during 16 thermography. Since the first reading was taken immediately when the patient entered the 17 room, it is likely that, after some minutes, there is some stabilization of the subject at the 18 room temperature that affects the absolute measurements. This observation suggests that a 19 stabilization period of the subject at the room temperature is recommended before the 20 thermograph exam in order to guarantee an effective measurement. This is in line with 21 available guidelines suggesting that thermography measures should be taken after a 22 stabilization period of 15-20 minutes to allow equilibrating with the environment. ${ }^{12,13}$

23 Our data also suggest that FIT is a reliable procedure in detecting the cold patch location in 24 headache patients and that the AI parameter is able to localize the cold patch even when the 25 patient referred a bilateral pain before the image is recorded. In previous studies, no 
1 correlation was found between FIT measurements and pain side or VAS score in patients ${ }^{5,18}$.

2 Instead, our results demonstrate that the Asymmetry Index defined by Kurth et al. ${ }^{19}$ well

3 describe the lateralization of cold patch in patients. Moreover, AI index correlates with

4 doctor's visual inspection of FIT and in case of unilateral pain there is a good correlation

5 between AI and pain side. Even if the correlation between AI and VAS score is low, AI index

6 could be a useful tool in order to localize the pathological side (where there is the coldpatch)

7 in each patient. Our results further confirm that regardless to patient's perception, the cold

8 patch can be viewed as a "unilateral" entity, representing the neurochemical imbalance

9 between the two sides in terms of microcirculation in the facial district. This hypothesis is in 10 line with neurophysiological studies on Visual Evoked Potentials showing a prominent 11 laterality of neurophysiological signatures in headache ${ }^{20-24}$. Therefore, the AI estimated by 12 FIT can have a relevant prognostic role going beyond patient's perception.

13 Finally, the SideDifference parameter was able to discriminate headache patients from 14 controls, even if the FIT image was taken with patients experiencing different pain intensities.

15 These observations suggest that FIT can be a useful neurophysiological aid in the diagnosis 16 for pain medicine. An add-on marker in diagnosis may be useful in difficult case or when 17 there is a risk for diagnostic mistakes concerning unilateral or bilateral headaches form ${ }^{26}$. We 18 foresee the time when FIT could be used in evaluating pharmacological and non19 pharmacological treatment in headache and other facial neuralgia: FIT with a commercially 20 available camera is a relatively inexpensive procedure that can be used in headache and pain 21 centre setting.

22 However, even though promising, our results were obtained in a relatively small number of 23 subjects, and acquisitions followed a shared protocol that guaranteed consistency across 24 subjects. Therefore, for future applications, it will be important to create a consensus 25 procedure for FIT acquisition, able to support diagnosis. 
1 From a practical viewpoint, in the current therapeutic scenario, where non-invasive

2 neuromodulation techniques are increasingly used for the treatment of migraine [21-23][25-

3 27] , these results can reach an even more interesting meaning. In fact, transcranial direct 4 current stimulation (tDCS) has been proposed for the treatment of migraine ${ }^{27,28,30,31}$. tDCS is

5 a non-invasive technique that acts sub-threshold $(<1 \mathrm{~V} / \mathrm{m}$ vs. $100 \mathrm{~V} / \mathrm{m}$ produced by other

6 supra-threshold techniques ${ }^{32}$, producing an excitability change in the area below the electrode.

7 Even though the electric field induced by tDCS spread over neighbouring areas, the electrode

8 montage is a crucial element in the optimization of tDCS therapy ${ }^{29}$. In migraine, electrodes

9 are usually placed in the frontal area, according to patient's perception and subjective 10 analysis. Conversely, the cold patch, representing a vasoconstriction area characterizing the 11 migraine may be an effective target for neuromodulation intervention. In migraine patients, 12 the cold patch corresponds to a vasoconstriction within the external carotid territory, which 13 represents the end result of the haemodynamic changes due to the activity of the autonomic 14 and the trigeminovascular systems. In this case, cathodal tDCS over this area may reduce the 15 pathological frontal asymmetry. For this reason, the automatic localization of cold patch using 16 FIT based parameters, as proposed in this study, can be applied for the optimization of tDCS 17 treatment in migraine patients.

18 Taken together, our results suggest that FIT could be useful as a diagnostic tool, to localize 19 the cold patch and to study of unilateral headache without side shift like Cluster Headache, 20 Paroxysmal Hemicrania, SUNCT or cranial neuralgias (trigeminal neuralgia). However, the 21 case series is relatively small in order to evaluate the sensitivity and specificity of FIT in 22 discriminating between different headache entities. In addition, even though at present there is 23 no strong evidence supporting the change of FIT after a pharmacological or non24 pharmacological treatment, the use tDCS or prophylactic agents (beta blockers, Calcium 
1 antagonist ) show a tendency to reducing or disappearing of FIT asymmetry, thus suggesting

2 the use of FIT also as a prognostic tool.

3

4 Conclusions

5 In conclusion, in respect to previous studies, this work introduces the possibility to use

6 modern commercial infrared thermal camera for the analysis of frontal thermography in

7 migraine patients. Moreover, two new parameters (AI and Side Difference) provided

8 meaningful results, being one able to localize the cold patch and the other one able to

9 distinguish patients from controls.

10

11

12 Article Highlights

13 - The use of Frontal Infrared Thermography (FIT) in the diagnosis of primary 14 headaches is still debated.

15 - In this study, we showed that FIT measurements have good reproducibility even when 16 using commercial cameras in both patients and controls.

17 - We defined a new parameter, the Side Difference, that is able to discriminate patients 18 with headache from controls.

19 - We defined another parameter, the Asimmetry Index, that correlates with the side of 20 pain.

21 - FIT can be used to characterize vascular changes in chronic migraine patients but 22 standardized recording conditions are needed to guarantee reliability. 
1

2

3

4

5

6

7

8

9

10

11

12

13

14

15

16

17

18

19

20

21

22

23

24

25

26

27

28

29

30

31

32

33

34

35

36

37

\section{$\underline{\text { References }}$}

1. Szentkuti A, Kavanagh HS, Grazio S. Infrared thermography and image analysis for biomedical use. Period Biol 2011; 113: 385-392.

2. Haddad DS, Brioschi ML, Baladi MG, et al. A new evaluation of heat distribution on facial skin surface by infrared thermography. Dentomaxillofacial Radiol 2016; 45: 20150264.

3. Swerdlow B, Dieter JN. The Validity of the Vascular 'Cold Patch' in the Diagnosis of Chronic Headache. Headache J Head Face Pain 1986; 26: 22-26.

4. Edmeads J. Is thermography a marker for vascular headaches? Headache 1986; 26: 47.

5. Swerdlow B, Dieter JN. The vascular 'cold patch' is not a prognostic index for headache. Headache 1989; 29: 562-568.

6. Dalla Volta G, Anzola GP. Are There Objective Criteria to Follow Up Migrainous Patients? A Prospective Study with Thermography and Evoked Potentials. Headache J Head Face Pain 1988; 28: 423-425.

7. Dalla Volta G, Anzola GP, DiMonda V. The disappearance of the 'cold patch' in recovered migraine patients: thermographic findings. Headache 1991; 31: 305-309.

8. Drummond PD, Lance JW. Facial temperature in migraine, tension-vascular and tension headache. Cephalalgia Int J Headache 1984; 4: 149-158.

9. Drummond PD, Lance JW. Thermographic changes in cluster headache. Neurology 1984; 34: 1292-1298.

10. Zaproudina N, Närhi M, Lipponen JA, et al. Nitroglycerin-induced changes in facial skin temperature: 'cold nose' as a predictor of headache? Clin Physiol Funct Imaging 2013; n/a-n/a.

11. Headache Classification Committee of the International Headache Society (IHS). The International Classification of Headache Disorders, 3rd edition (beta version).

Cephalalgia Int J Headache 2013; 33: 629-808.

12. American Academy of Thermology. Guidelines for neuro-musculoskeletal infrared medical thermography and sympathetic skin response (SSR) studies, https://aathermology.org/organization-2/guidelines/guidelines-for-neuromusculoskeletal-thermography/ (accessed 12 June 2018).

13. Schwartz RG, Getson P, O'Young B, et al. Guidelines for Dental-Oral and Systemic Health Infrared Thermography. Pan Am J Med Thermol 2015; 2: 44-53.

14. Fleiss JL. The Design and Analysis of Clinical Experiments: Fleiss/The Design. Hoboken, NJ, USA: John Wiley \& Sons, Inc. Epub ahead of print 8 February 1999. DOI: $10.1002 / 9781118032923$.

15. Lexell JE, Downham DY. How to assess the reliability of measurements in rehabilitation. Am J Phys Med Rehabil 2005; 84: 719-723. 
16. Antonaci F, Sand T, Lucas GA. Pressure algometry in healthy subjects: inter-examiner variability. Scand J Rehabil Med 1998; 30: 3-8.

3

17. Shrout PE, Fleiss JL. Intraclass correlations: uses in assessing rater reliability. Psychol Bull 1979; 86: 420-428.

18. Ford R, Ford K. Thermography in the Diagnosis of Headache. Semin Neurol 1997; 17: 343-349.

19. Kurth F, Gaser C, Luders E. A 12-step user guide for analyzing voxel-wise gray matter asymmetries in statistical parametric mapping (SPM). Nat Protoc 2015; 10: 293-304.

20. Anzola GP, Dalla Volta G, Di Monda V, et al. Laterality Indexes In Primary Headache : Teletermography, Visual Evoked Potentials, Reaction Times. Cephalalgia 1987; 7: 301301.

21. Kudrow L. Thermographic and Doppler Flow Asymmetry in Cluster Headache. Headache J Head Face Pain 1979; 19: 204-208.

22. Gawel M, Connolly JF, Rose FC. Migraine Patients Exhibit Abnormalities in the Visual Evoked Potential. Headache J Head Face Pain 1983; 23: 49-52.

23. Raudino F. Visual evoked potential in patients with migraine. Headache 1988; 28: 531533.

24. Boylu E, Domaç FM, Koçer A, et al. Visual evoked potential abnormalities in migraine patients. Electromyogr Clin Neurophysiol 2010; 50: 303-308.

25. Drummond PD. Vascular Changes in Atypical Facial Pain. Headache J Head Face Pain 1988; 28: 121-123.

26. Voiticovschi-Iosob C, Allena M, De Cillis I, et al. Diagnostic and therapeutic errors in cluster headache: a hospital-based study. $J$ Headache Pain 2014; 15: 56.

27. Antal A, Kriener N, Lang N, et al. Cathodal transcranial direct current stimulation of the visual cortex in the prophylactic treatment of migraine. Cephalalgia Int $J$ Headache 2011; 31: 820-828.

28. Dasilva AF, Mendonca ME, Zaghi S, et al. tDCS-induced analgesia and electrical fields in pain-related neural networks in chronic migraine. Headache 2012; 52: 1283-1295.

29. DaSilva AF, Truong DQ, DosSantos MF, et al. State-of-art neuroanatomical target analysis of high-definition and conventional tDCS montages used for migraine and pain control. Front Neuroanat 2015; 9: 89.

30. Magis D. Neuromodulation in migraine: state of the art and perspectives. Expert Rev Med Devices 2015; 12: 329-339.

31. Viganò A, D'Elia TS, Sava SL, et al. Transcranial Direct Current Stimulation (tDCS) of the visual cortex: a proof-of-concept study based on interictal electrophysiological abnormalities in migraine. $J$ Headache Pain 2013; 14: 23. 
1 32. Dmochowski JP, Datta A, Bikson M, et al. Optimized multi-electrode stimulation

2 increases focality and intensity at target. J Neural Eng 2011; 8: 046011.

\section{Figures legends}

4 Figure 1- Measurement point identification in patients. The radius of the circle was calculated 5 as the distance between the Nasion and the coolest point in the cold patch. Once defined the 6 radius, the second point was the point equidistant from the Nasion and with the same vertical 7 coordinate of the first point of measurement (symmetric point).

8

9 Figure 2- Measurement point identification in controls. The radius of the circle was constant.

10

11 Figure 3 - Mean FIT measured over 20 controls (left side) and 15 patients (right side) in 12 three consecutive readings ( $\mathrm{m} 1, \mathrm{~m} 2, \mathrm{~m} 3$ - $\mathrm{x}$ axis) with 10 minutes of rest between readings 13 during T1 and T2. Error bars represent standard errors.

14

15 Figure 4 - Difference between left and right side as a percentage of the average temperature 16 in forehead (SideDifference) in patients $(\mathrm{N}=20)$ and controls $(\mathrm{N}=15)$. 


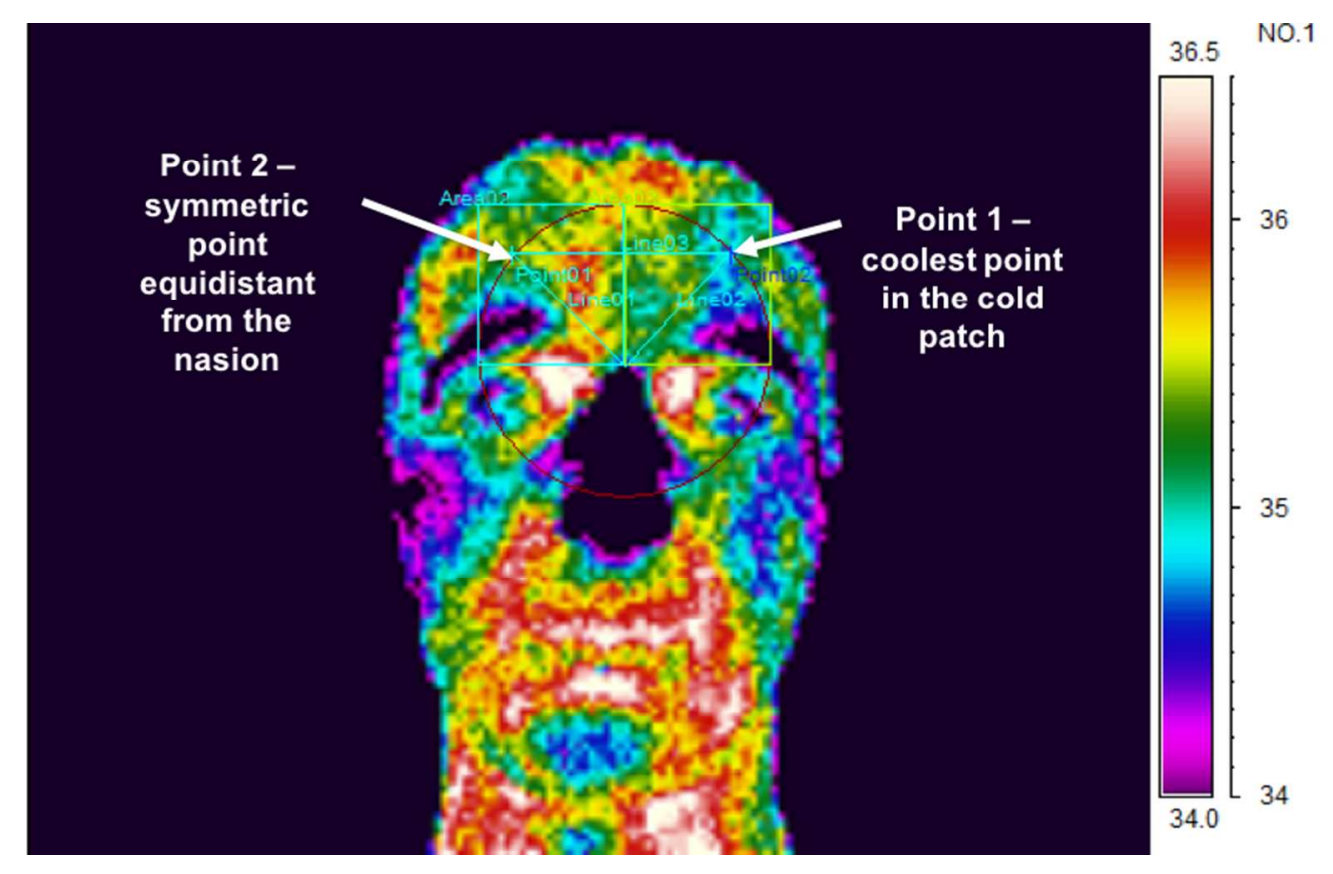

Figure 1

297x190mm (72 x 72 DPI) 


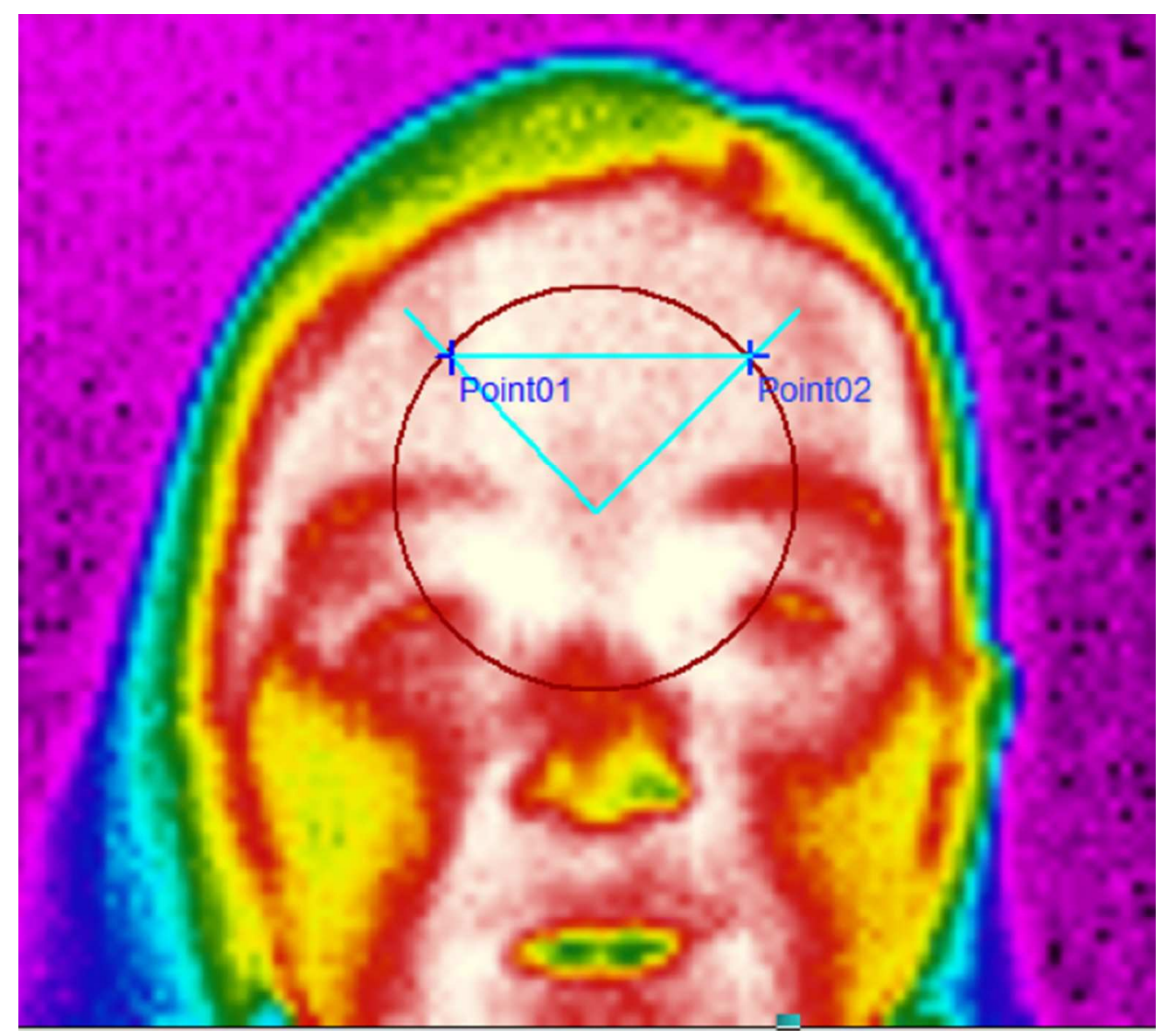

Figure 2

$213 \times 190 \mathrm{~mm}(72 \times 72$ DPI $)$ 


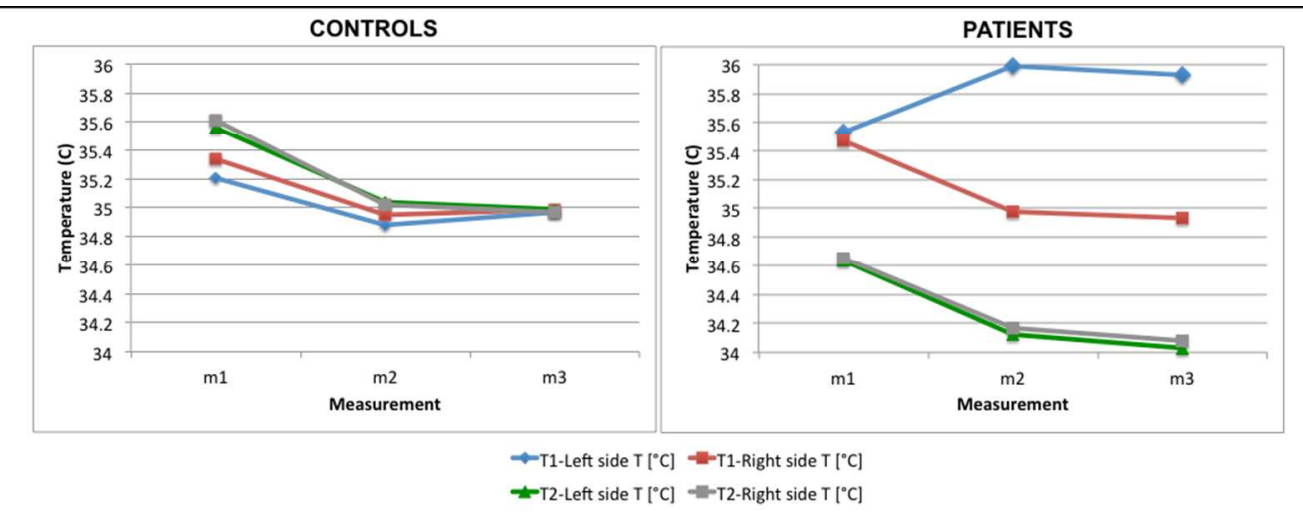

Figure 3

$360 \times 141 \mathrm{~mm}(72 \times 72 \mathrm{DPI})$ 


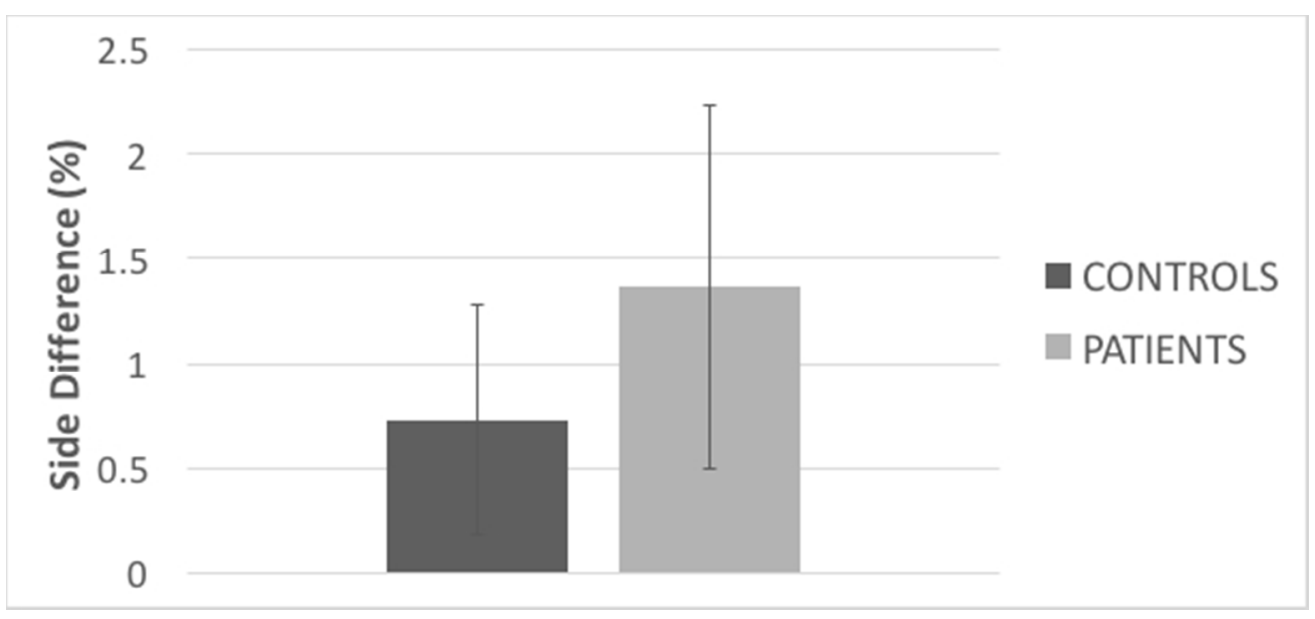

Figure 4

$215 \times 98 \mathrm{~mm}(72 \times 72$ DPI $)$ 


\section{STROBE Statement - checklist of items that should be included in reports of observational/case controlled studies, etc. YOU MUST NOTE THE PAGE NUMBER WHERE EACH ITEM IS REPORTED INSIDE BRACKETS [ ] FOR EACH ITEM \#. IF NOT APPLICABLE WRITE N/A}

\begin{tabular}{|c|c|c|}
\hline & $\begin{array}{c}\text { Item } \\
\#\end{array}$ & Recommendation \\
\hline \multirow[t]{2}{*}{ Title and abstract } & 1 & (a) Indicate the study's design with a commonly used term in the title or the abstract \\
\hline & [3] & $\begin{array}{l}\text { (b) Provide in the abstract an informative and balanced summary of what was done } \\
\text { and what was found }\end{array}$ \\
\hline
\end{tabular}

\begin{tabular}{lcl} 
Introduction & 2 & Explain the scientific background and rationale for the investigation being reported \\
\hline Background/rationale & {$[4]$} & \\
\hline Objectives & $\begin{array}{c}\text { [5/6] } \\
\text { Methods }\end{array}$ & State specific objectives, including any prespecified hypotheses \\
\hline Study design & 4 & Present key elements of study design early in the paper \\
\hline Setting & {$[7]$} & $\begin{array}{l}\text { Describe the setting, locations, and relevant dates, including periods of recruitment, } \\
\text { exposure, follow-up, and data collection }\end{array}$ \\
\hline Participants & $\begin{array}{l}\text { (a) Cohort study - Give the eligibility criteria, and the sources and methods of } \\
\text { selection of participants. Describe methods of follow-up } \\
\text { Case-control study - Give the eligibility criteria, and the sources and methods of } \\
\text { case ascertainment and control selection. Give the rationale for the choice of cases } \\
\text { and controls } \\
\text { Cross-sectional study - Give the eligibility criteria, and the sources and methods of } \\
\text { selection of participants }\end{array}$ \\
\hline
\end{tabular}

(b) Cohort study-For matched studies, give matching criteria and number of exposed and unexposed

Case-control study - For matched studies, give matching criteria and the number of controls per case

\begin{tabular}{|c|c|c|}
\hline Variables & $\begin{array}{c}7 \\
{[7-9]}\end{array}$ & $\begin{array}{l}\text { Clearly define all outcomes, exposures, predictors, potential confounders, and effect } \\
\text { modifiers. Give diagnostic criteria, if applicable }\end{array}$ \\
\hline $\begin{array}{l}\text { Data sources/ } \\
\text { measurement }\end{array}$ & $\begin{array}{c}8^{*} \\
{[7-9]}\end{array}$ & $\begin{array}{l}\text { For each variable of interest, give sources of data and details of methods of } \\
\text { assessment (measurement). Describe comparability of assessment methods if there is } \\
\text { more than one group }\end{array}$ \\
\hline Bias & $\begin{array}{c}9 \\
{[\mathbf{n} / \mathbf{a}]}\end{array}$ & Describe any efforts to address potential sources of bias \\
\hline Study size & $\begin{array}{c}10 \\
{[\mathbf{n} / \mathbf{a}]}\end{array}$ & Explain how the study size was arrived at \\
\hline Quantitative variables & $\begin{array}{c}11 \\
{[7-9]}\end{array}$ & $\begin{array}{l}\text { Explain how quantitative variables were handled in the analyses. If applicable, } \\
\text { describe which groupings were chosen and why }\end{array}$ \\
\hline \multirow[t]{4}{*}{ Statistical methods } & 12 & (a) Describe all statistical methods, including those used to control for confounding \\
\hline & [7-9] & (b) Describe any methods used to examine subgroups and interactions \\
\hline & & (c) Explain how missing data were addressed \\
\hline & & $\begin{array}{l}\text { (d) Cohort study-If applicable, explain how loss to follow-up was addressed } \\
\text { Case-control study-If applicable, explain how matching of cases and controls was }\end{array}$ \\
\hline
\end{tabular}


1

2

3

4

5

6

7

8

10

11

12

13

14

15

16

17

18

19

20

21

22

23

24

25

26

27

28

29

30

31

32

33

34

35

36

37

38

39

40

41

42

43

44

45

46

47

48

49

50

51

52

53

54

55

56

57

58

59

60 addressed

Cross-sectional study - If applicable, describe analytical methods taking account of sampling strategy

(e) Describe any sensitivity analyses

Continued on next page 


\begin{tabular}{|c|c|c|}
\hline \multicolumn{2}{|l|}{ Results } & \multirow[b]{2}{*}{$\begin{array}{l}\text { (a) Report numbers of individuals at each stage of study-eg numbers potentially eligible, } \\
\text { examined for eligibility, confirmed eligible, included in the study, completing follow-up, } \\
\text { and analysed }\end{array}$} \\
\hline Participants & $\begin{array}{c}13^{*} \\
{[\mathbf{n} / \mathbf{a}]}\end{array}$ & \\
\hline & & (b) Give reasons for non-participation at each stage \\
\hline & & (c) Consider use of a flow diagram \\
\hline \multirow[t]{3}{*}{$\begin{array}{l}\text { Descriptive } \\
\text { data }\end{array}$} & $\begin{array}{l}14^{*} \\
{[6]}\end{array}$ & $\begin{array}{l}\text { (a) Give characteristics of study participants (eg demographic, clinical, social) and } \\
\text { information on exposures and potential confounders }\end{array}$ \\
\hline & & (b) Indicate number of participants with missing data for each variable of interest \\
\hline & & (c) Cohort study-Summarise follow-up time (eg, average and total amount) \\
\hline \multirow[t]{3}{*}{ Outcome data } & $15^{*}$ & Cohort study - Report numbers of outcome events or summary measures over time \\
\hline & {$[\mathbf{n} / \mathbf{a}]$} & $\begin{array}{l}\text { Case-control study - Report numbers in each exposure category, or summary measures of } \\
\text { exposure }\end{array}$ \\
\hline & & Cross-sectional study—Report numbers of outcome events or summary measures \\
\hline \multirow[t]{3}{*}{ Main results } & $\begin{array}{c}16 \\
{[\mathbf{n} / \mathbf{a}]}\end{array}$ & $\begin{array}{l}\text { (a) Give unadjusted estimates and, if applicable, confounder-adjusted estimates and their } \\
\text { precision (eg, } 95 \% \text { confidence interval). Make clear which confounders were adjusted for } \\
\text { and why they were included }\end{array}$ \\
\hline & & (b) Report category boundaries when continuous variables were categorized \\
\hline & & $\begin{array}{l}\text { (c) If relevant, consider translating estimates of relative risk into absolute risk for a } \\
\text { meaningful time period }\end{array}$ \\
\hline Other analyses & $\begin{array}{c}17 \\
{[10-} \\
12]\end{array}$ & $\begin{array}{l}\text { Report other analyses done - eg analyses of subgroups and interactions, and sensitivity } \\
\text { analyses }\end{array}$ \\
\hline Discussion & & 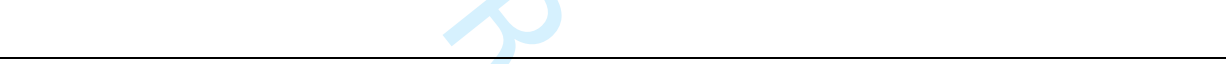 \\
\hline Key results & $\begin{array}{c}18 \\
{[12]}\end{array}$ & Summarise key results with reference to study objectives \\
\hline Limitations & $\begin{array}{c}19 \\
{[13]}\end{array}$ & $\begin{array}{l}\text { Discuss limitations of the study, taking into account sources of potential bias or imprecision. } \\
\text { Discuss both direction and magnitude of any potential bias }\end{array}$ \\
\hline Interpretation & $\begin{array}{c}20 \\
{[12-} \\
13]\end{array}$ & $\begin{array}{l}\text { Give a cautious overall interpretation of results considering objectives, limitations, } \\
\text { multiplicity of analyses, results from similar studies, and other relevant evidence }\end{array}$ \\
\hline Generalisability & $\begin{array}{c}21 \\
{[13-} \\
14]\end{array}$ & Discuss the generalisability (external validity) of the study results \\
\hline
\end{tabular}

Other information

Funding 22 Give the source of funding and the role of the funders for the present study and, if

[15] applicable, for the original study on which the present article is based

*Give information separately for cases and controls in case-control studies and, if applicable, for exposed and unexposed groups in cohort and cross-sectional studies.

Note: An Explanation and Elaboration article discusses each checklist item and gives methodological background and published examples of transparent reporting. The STROBE checklist is best used in conjunction with this article (freely available on the Web sites of PLoS Medicine at http://www.plosmedicine.org/, Annals of Internal Medicine at http://www.annals.org/, and Epidemiology at http://www.epidem.com/). Information on the STROBE Initiative is available at www.strobe-statement.org. 